\title{
'Bringing more than I contain': ethics, curriculum and the pedagogical demand for altered egos
}

\author{
SHARON TODD
}

\begin{abstract}
Building from the notion that learning occasions an 'ontological' violence, this paper examines the ethical relations implicated in pedagogy and curriculum. In particular, it explores ways in which pedagogy is rooted in a demand for students to alter their egos, and, thereby, draws attention to the delicate nature of the teaching-learning relationship. Appealing to the ethical philosophy of Emmanuel Levinas, it discusses how ethical, non-violent relations are made possible in the day-to-day encounters between teachers and students. A reading of one of Melanie Klein's case studies highlights the specific ways teachers participate in ego-alteration at the same time as they participate in conditions for establishing ethical relations. The paper concludes with a discussion of these conditions and the role that curriculum plays in responsible teaching.
\end{abstract}

Curriculum is central in educating students to become certain kinds of people, individuals or citizens-whether such curriculum builds on students' own interests (Dewey 1969) or is based on state-controlled outcomes (Wien and Dudley-Marling 1998). In both cases, there is an underlying assumption about what it means to learn and be 'educated'; indeed, who educators think students should become frequently defines the aims and purpose of educational practices. But what if attempts to realize even the most progressive or open-ended of aims (e.g. through emergent curriculum or student-centred learning) enact an inevitable violence upon the very subjects being educated? In other words, what if learning itself (and not curriculum per se) enacts an 'ontological' or 'metaphysical' violence (Derrida 1978) - a violence which accompanies the very constitution of subjectivity? Indeed, if learning is the process through which each individual being becomes a subject or self and, as such, is marked by the pains, struggles, renunciations and frustrations that accompany such growth and change (Castoriadis 1997), how might educators then think of curriculum?

I examine these questions through a close examination of the teachinglearning relationship, appealing to the ethical philosophy of Emmanuel Levinas and the psychoanalytic thought of Melanie Klein and Cornelius Castoriadis, in order to consider what is ethically at stake in asking students to learn. In particular, I explore how the pedagogical demand for learning also functions as a demand for students to alter themselves, to become

Sharon Todd, assistant professor in the Faculty of Education, York University, 4700 Keele St., Toronto, Ontario, Canada, M3J 1P3; e-mail: stodd@edu.yorku.ca, has edited Learning Desire: Perspectives on Pedagogy, the Culture and the Unsaid (New York: Routledge, 1997). She is currently writing a book for SUNY Press tentatively entitled The Other Side of Pedagogy: Exploring Intersections Between Levinasian Ethics and Psychoanalysis. 
different people from what they were prior to the learning encounter. Here, I consider the ways in which the ontological possibilities of teaching and learning are intertwined with the conditions for establishing ethical relations, conditions that enable a more fulsome consideration of the ethical dimension of curriculum itself.

\section{'Learning to become' and the pedagogical demand for altered egos}

Pedagogy starts at age zero and no one knows when it ends. The aim of pedagogy (or paideia) - I am of course speaking normatively-is to help the newborn hopeful and dreadful monster to become a human being, to help this bundle of drives and imagination to become an anthropos ... . The point of pedagogy is not to teach particular things, but to develop in the subject the capacity to learn ... (Castoriadis 1997: 129).

As a philosopher and political theorist, Castoriadis opens up the question of pedagogy, of learning and teaching, to the conditions of a person's becoming. He proposes that along the trajectory of subjecthood, from one's beginning as a 'hopeful and dreadful monster' to one's finale in death, pedagogy turns on the ability of the nascent subject to change, to alter, to become something other than what it was. The subject accomplishes this self-alteration through its capacity to negotiate meaning in the world in relation to the objects and persons around it. Castoriadis draws attention to how subjectivity is instituted; that is, how the nascent human subject is eminently pliable and is potentially fitted into any social order into which it happens to be born. But, Castoriadis is also a psychoanalyst and, as such, speaks of the project of 'becoming' in terms of the development of the ego, glossing the famous Freudian adage, 'Where Id was, there Ego shall become'. What it means to learn, for Castoriadis, is to learn to become an ego, and it is in this process of learning where the subject is both shaped by and yet resists the forces of social circumstance. ${ }^{1}$

Like Freud, Castoriadis suggests that 'learning to become' is an inherently violent activity where the social environment exacts a traumatic price from the psyche. The subject, through making symbolic connections to its environment, must relinquish its own unconscious desires and drives in the service of sociality. It renounces, represses and sublimates its 'bundle of drives' in a struggle to negotiate with what is always necessarily 'outside' and 'other' to the subject itself. It is precisely through this negotiation that the subject learns to take pleasure and delight in the external world, and learns to control itself, as best it can, for the purpose of making relationships to Others. For Castoriadis (1991), the psyche is, thereby, necessarily 'coerced' into becoming a being-a social individual, an ego-through the social institutions (e.g. the family, school, and religion) that furnish the subject with meaning, that impose limitations upon the subject's desires and drives. ${ }^{2}$ Yet, for Castoriadis, there is always a residue, a psychical remainder that cannot be subsumed into the social order and which allows for the possibility that subjects will make meaning and learn in unpredictable ways. 
In some ways, Castoriadis' radical insight is both simple and familiar: the subject learns to become a being in relation to others it encounters, learning values, behaviours and modes of thinking within the nexus of culture, language and social relations. However, rather than taking a naïve view of this process, Castoriadis sees that this is an inevitably violent demand society places on its subjects. Through social institutions, society exerts a force upon the subject to become, for example, a worker, citizen or consumer (or in other social-historical circumstances, feudal lords, peasants or anointed kings). Insofar as education is a socializing institution par excellence, what Castoriadis underscores here is not only the need to speak of the violence in education, but the violence of education. ${ }^{3}$

Castoriadis' portrayal is helpful for examining a major assumption underlying education: that educators teach in the hope that others will learn and change. Yet, at the same time, it challenges education's innocence. 'Learning to become' depicts well the ontological stakes in processes of learning, both with respect to the benefits of change and the high prices to be paid in terms of the coercive nature of subject formation. It echoes the comments students often make when they begin to think and experience their own lives differently through new ideas, concepts, and relationships to other people. It is not uncommon, for example, to hear even adult students say, 'I have never thought of myself this way before reading this book', or, 'My life has changed as a result of taking this class'. My own educational history speaks to such moments of elation. These declarations of change, however, are often accompanied by statements of struggle in making a relationship to a knowledge 'outside' the subject; students wrestle with the otherness and difference presented to them through the curriculum and through the bodies of teachers and students they encounter. Reading through Castoriadis' perspective, such difficulty suggests that there is something profoundly at risk in coming to know, involving renunciations and sacrifices sometimes too great to bear. Students often feel that once they struggle to know something, they can never be quite the same again. And, as if this struggle were not enough, the process continually returns, refusing to offer consolation for very long. Egos are not formed, nor are desires done away with once and for all. The ego is never finished, but always incomplete; not 'an attained state but ... an active situation' (Castoriadis 1987: 104). This means the ego is continually vulnerable to the potentiality of violence, to the recurrence of 'learning to become'.

Pedagogically speaking, the simplicity of Castoriadis' insight is deceptive, for, although it seems to depict, in a straightforward fashion, the ontological possibilities of learning, it also highlights the ethical aspects of learning itself, insofar as learning is accompanied by a certain violence to the subject. To illustrate this point, consider the following example written by a student teacher reflecting upon an experience in a grade 1 class:

At the beginning of the morning, children change their outside shoes to inside shoes, take off jackets and place them along with their knapsacks on coat hooks in the classroom cupboard. At 8:50 am, students are sitting on the carpeted area of the classroom and stand for ' $O$ Canada' that is announced over the public address system. The students have been instructed not to 
move or talk. I hear crying from a girl that is standing at the back of the room. The host teacher ignores the crying and continues to sing 'O Canada' with the rest of the class. I walk directly to the girl that is crying. I ask the girl if she is hurt. She says, 'No'. I then ask the girl why she is crying. She says, 'I could not go to the washroom because we can't move during "O Canada" '. I notice her legs are rubbing against each other. I whisper in the girl's ear if she is wet. The student says 'Yes'. She cries louder. The host teacher continues to stand and looks away from me as I look at him. I take the girl and we walk outside the class toward the health room (Student essay, December 1998).

Explored from Castoriadis' point of view, the girl portrayed here has learned to become a student who obeys the rules and procedures around a particular activity. Part of what is demanded is that the student control, however unsuccessfully in the final analysis, her own desires and needs in the service of performing a social ritual, the singing of the national anthem. In her own words, what she has learned is, 'I could not go to the washroom because we can't move during “O Canada', '. The ego here understands the limitations and restrictions placed upon it by an external force: the school routine, the teacher's rules. She symbolizes that relationship in a particular way, associating the singing of the anthem with bodily stillness and control. Such symbolization displays a mode of understanding that incorporates the coercive impulse of education, where subjectivity is forged within the demands placed upon it, and, as Klein (1992: 221) observes, such symbolism 'is the basis of the subject's relation to the outside world and to reality in general'. The turn to language to explain her subjection simultaneously signals her entry into subjecthood. ${ }^{4}$

In retelling the incident, it is also evident that the student teacher is struggling to symbolize her relationship to the girl, to the host teacher, and to herself. By writing her scenario in the present rather than past tense, she is doing more than merely describing un temps perdu; instead, her retelling suggests an ongoing engagement with a past that continues to haunt her present. The incident is not simply an event that has passed without comment, like so many others that occur throughout her day, but participates in her negotiations of what it means to be a student and a teacher. Does becoming a teacher necessarily mean learning to make certain concessions to rules and routines that might be hurtful, at times, to students in the class? A mature and thoughtful woman, she, too, is subject to an event that has challenged her sensibilities, that is demanding of her to participate in something-and become someone-to which she is utterly resistant, and from which she attempts to distinguish herself. The scene crystallizes a certain understanding of the culture of schooling, and it is the student teacher's continual resistance to rules at the expense of human relationships that marks her (ambivalent) entry into this culture. The witnessing of the event provokes a crisis to which she responds by retelling it as a story in which she is not like the host teacher: she approaches the girl who is in tears, 'disobeying' the established rules and routines. In her resistance, and in her attempt to work through the crisis this incident has provoked for her, she in effect splits teacher as an 'institutional figure' from teacher as a 'compassionate person'. However, what is of particular 
significance for my purposes here is not an interpretation of the content of her retelling (e.g. the splitting, the distancing from the teacher), but how the act of retelling attempts to capture her experience of learning as a form of coercion. Learning to be a teacher at this point is akin to learning to act like a teacher and, as this incident revealed to her, such learning is placing certain (undesirable) demands on who she is.

The coercive force of education is here doubled: in seeking to articulate a position for herself that can only be caught within the tensions of being part teacher/part student, the student teacher offers a narrative that both reveals the violence of learning to become a teacher and the violence of learning to become a student. The retelling, as a form of symbolization, suggests, like the girl's own symbolic articulations, that learning to become (and the future toward which it beckons) can be fraught with anguish and traumatic awareness.

There is, however, another moment present whereby the girl's learning to become a student and the student's learning to become a teacher are disrupted by another event: their relationship to each other. In this instance, there is another mode of relationality in evidence. The interaction between the girl and the student teacher inserts another possibility in the girl's understanding of her self in relation to the anthem and makes it possible for her to imagine that there are other forms of social relation available to her. Similarly, the reaching out of the student teacher to inquire of the young girl's situation suggests a capacity for a relationality not premised on control or coercion. There opens up the potential for a non-violent relationship, a relationship not based on denying or repudiating the student's needs (bodily needs in this case), but rooted in a response quite particular to the situation at hand.

In working with the idea that pedagogy is a process of 'learning to become' that involves violence, I consider below the ways non-violence might also be evident in pedagogical interactions. More to the point, I ask what are the conditions for ethicality even in the face of such ontological violence?

\section{'Learning to become' and the question of ethics}

As the example implies, the idea that pedagogy is about the demand for 'learning to become' crystallizes both the dream and nightmare of education itself. On the one hand, it touches on the hope that people can think differently, can change the way they relate to each other, and can form new understandings of themselves and the world that makes possible the very act of teaching and learning. As Britzman (1998: 10) writes of education, 'it demands of students and teachers that each come to something, make something more of themselves'. There is an implicit rising to the occasion, as it were, a demand for a certain kind of being in the classroom. On the other hand, the demand for 'learning to become' carries with it a great burden-for, if pedagogy is about the becoming of the subject, then it can become a tool for the most oppressive ends. Questions of a normative 
nature inevitably arise: who is it that we, as educators and citizens, desire people to become?

Philosophically speaking, exploring the place of ethics in education often begins from this normative point of departure: what values are to be invoked in educational encounters? How might students be educated to become better citizens, more responsible moral subjects, or people who can live and work better across social differences? Simon (1992: 62) notes that pedagogy is not just about the teaching of morals, but is itself a 'moral vision'. Normative questions are often central in helping to define and reflect upon an educational project.

However, posing normative questions has the tendency to make ethics programmatic in its orientation to education: a set of duties or obligations that if well-enough defined and well-enough followed will produce the ethical behaviour desired. Bauman (1993: 20) remarks of men and women living in a post-modern world, 'we look in vain for the firm and trusty rules which may reassure us that once we followed them, we could be sure to be in the right'. Education is seen as a fulfilment or failure of prior principles of goodness and rightness-prior, that is, to the actual face-to-face encounters between teachers and students. In such an understanding, ethics comes to education from the outside, it asks education, often through appeals to empathy, or reason, or politics, or moral imperative, to become a better practice, to think about how it imagines its ideals; it also asks education to consider what students have to learn and how teachers and students need to act in order to ensure the realization of such ideals. What it often forgets is the uncertainty and unpredictability of the pedagogical encounter itself.

But, what if one begins from a slightly different place-with the 'messy and ambiguous' (Bauman 1993 : 32) nature of human reality? What if one reflects upon the failure and uncertainty of the demand for 'learning to become'? As Phillips (1998: 412) suggests, 'people can never know beforehand, neither can their teachers, exactly what is of personal significance'; an individual 'picks out and transforms the bits [s] he wants, the bits that can be used in the hidden projects of unconscious desire'. At the same time as pedagogy demands that its subjects 'learn to become', in practice there is a great deal of uncertainty and unpredictability to the pedagogical enterprise. People bring a host of idiosyncrasies and unconscious associations that enable them to resist, transform and create symbolic attachments which pedagogy cannot predict or control. Could the host teacher, in the above example, predict that the girl would so rigidly attach to the idea of bodily immobility that she would forfeit her own bodily needs? It may not be surprising, but is it a sure thing?

Instead of asking what education ought to be, what if educators ask what makes ethics possible in education in the first place, particularly in light of the latter's uncertainty and its ontological entanglements with 'learning to become'? What makes education receptive, perhaps even vulnerable, to ethicality? Taking my cue from Levinas, who holds that ethicality consists in the non-violent relationship to the Other, in the particular relation the Self has to another person, I look at the specificity of relationships within the pedagogical encounter as possibilities for ethics. ${ }^{5}$ 
Shifting the focus from education as a scene where one ought to apply this or that principle, to a scene where the conditions or contingencies of ethicality may be found, means no longer simply thinking about education in relation to ethics; rather, it means thinking about ethics through education. This means exploring the day-to-day details of pedagogical encounters to see what they might offer in putting forth an understanding of education as a site of implied, rather than applied, ethics. To explore this idea of implied ethics more fully necessitates reading teaching-learning encounters for the way they promote conditions for ethicality as they promote conditions for being, both of which involve relationships between Self and Other.

\section{Teaching as 'bringing more than I contain' and learning as receiving}

Levinas is helpful in fleshing out pedagogical encounters, for he centres otherness at the very heart of teaching-learning. But, what he means by 'otherness' is important to highlight here. It does not simply mean a sociological other who is marginalized or maligned; nor does it simply signify another person who, as a subject, resembles oneself. Simply put, for Levinas (1987: 83), 'the Other is what I myself am not'. In Levinas' view, Self and Other exist as radically distinct beings; the Other is not 'like me', nor am I 'like the Other'. ${ }^{6}$ Moreover, whatever psychical bridges a Self does make with the Other, such as identification or empathy, merely serve to underscore the chasm that in fact separates the two. What is important for my purposes here is that it is in the very break between Self and Other where Levinas locates both the conditions for ethicality and the possibility for teaching and learning. Like Castoriadis, in this regard, it is that which is 'outside' the subject that provokes learning and alteration: the Other ruptures a sense of unified being.

Levinas (1969: 51) suggests that teaching is about staging an encounter with the Other, with something outside the Self, whereas learning is to receive from the Other more than the Self already holds.

It is ... to receive from the Other beyond the capacity of the I, which means exactly: to have the idea of infinity. But this also means: to be taught. The relation with the Other, or Conversation, is ... an ethical relation; but inasmuch as it is welcomed this conversation is a teaching [enseignement]. Teaching is not reducible to maieutics; it comes from the exterior and brings me more than I contain.

Note here how teaching and learning are conceived as an ethical relation, not because of some prescriptive injunction, but because there are present two distinct beings who come face-to-face in an encounter. For Levinas (1985: 67), teaching and learning, like ethics, lie in the 'insurmountability of the duality of beings'. The Other signifies a limitless possibility for the Self, and it is by coming face-to-face with such limitlessness that the Self can exceed its own containment, its own self-identity, breaking the solitude of being for the Self. In this view, teaching is only possible if the Self is 
open to the Other, to the face of the Other. Through such openness to what is exterior to the I, the I can become something different than, or beyond, what it was; in short, it can learn. ${ }^{7}$

This view of teaching as 'bringing more than I contain' is antithetical to the Socratic method that so predominates dialogical approaches to educational practice in which teaching is viewed as 'bringing out of the I that which it already contains'. The latter is, of course, more familiar: a pedagogy of recollection and self-knowledge, where the teacher as midwife facilitates the birth of students' knowledge. In the Socratic view, learning happens almost in spite of the teacher. It is the skill of the teacher to elicit that which is already 'inside' the subject, not the social encounter per se that matters. The maieutic method erases the significance of the Other, and claims that learning is a recovery contained within the $\mathrm{I}$, rather than a disruption of the I provoked by an Other in a moment of sociality. ${ }^{8}$ Levinas (1969: 43, ellipsis in original) writes: 'This primacy of the same was Socrates' teaching: to receive nothing of the Other but what is in me, as though from all eternity I was in possession of what comes to me from the outside...' In contrast, what is important to Levinas' view is that it is sociality-the encounter with the Other who is radically distinct from the self-that enables the self to learn and to change. By recentring the importance of teaching, Levinas compels educators to think about their responsibility in terms of this otherness, something that the Socratic view, because of its emphasis on what is self-same, cannot. By posing otherness as a condition of learning, Levinas' view underscores the point that teaching cannot abandon its ethical significance or run away from the possible consequences it generates.

Pedagogy see-saws between the 'bringing more than I contain' that teaching aspires to, and the 'receiving beyond the capacity of the I' that learning strives to achieve. Within this movement, of course, there are many surprises and shifts, and the roles marked out for teachers and students are not so rigid as perhaps they first appear. Heuristically, Levinas' focus on the centrality of otherness to teaching, learning and ethics lends insight into the demand for alteration pedagogy makes, and enables teachers to begin to consider what responsibilities they have towards those whom they teach. This is not to suggest that students do not have responsibilities themselves; their capacity to receive and be open to difference is certainly an ethical response, according to Levinas. But, the question that remains for educators is how, in the face of the violence implicit in the pedagogical demand for 'learning to become', might they be open and responsible to the Other?

Here is the crux of the tension. The subject can only become an ego if it is forced to repress or sublimate certain wishes and drives in the service of sociality; yet it must also be open, or receptive, to what is outside itself in order for this to occur. Teachers, as the vehicles through which the pedagogical demand for 'learning to become' is made real for students, can not escape their role-they require students to make symbolic attachments and meaning out of the curriculum they present, and in doing so can not escape a certain degree of coercion. It is not simply by repressing this coercion, by convincing ourselves that education is simply not coercive, 
that those committed to the project of education will arrive at ethical solutions which avoid this coercion. In fact, taking refuge in education's innocence denies the possibility of asking ourselves ethical questions, for it is precisely because violence is inherent to 'learning to become' and because teachers and students are continually vulnerable to each other in the face of this violence, that the question of non-violence can even be raised. As Levinas (1985: 86) himself writes, it is the potential to do violence that suggests its own reversal: 'The face is exposed, menaced, as if inviting us to an act of violence. At the same time, the face is what forbids us to kill'. Or elsewhere (Levinas 1969: 222): 'Only beings capable of war can rise to peace'.

For teachers, perhaps, participating in a non-violent relation to the Other means having to become a learner oneself, opening up oneself to the rupture of being that the face-to-face encounter entails. 'The face is a living presence; it is expression ... . The face speaks. The manifestation of the face is already discourse' (Levinas 1969: 66). Ethicality may rest in the teacher's own capacity to be receptive to the discourse of the face, to hear and listen for the meanings that students work out for themselves. Recall in the example above how the teacher could not face the girl or the student teacher; one can never know what motivated this turn away from the face, but can simply note that in turning away, the teacher could not receive the girl's vulnerability, be open to the meaning she construed between her body and the anthem, and, thus, foreclosed on the opportunity for response.

Thus far, what is at stake here for teachers are two valencies of interaction. On the one hand, there is the demand for 'learning to become', where teachers have a social obligation to offer students opportunities for encountering difference-to bring more than I contain. As has been discussed, however, the meanings students make are not cast beforehand, nor can teachers assume that fulfilling their obligations is not harmful. On the other hand, there can be a receptivity to what is unpredictably returned to the teacher: the meaning that students make and the vulnerabilities that accompany them. What I am suggesting here is that if educators demand that students make relationships to curriculum, and if these relationships are always uncertain and open to failure, then the place of ethicality in education lies in the failure of the demand for learning, what Britzman (1998: 140, n16) refers to as 'social, ontological, and epistemological breakdown'. It is here, in the moments in which students struggle for meaning, struggle to make sense out of and symbolize their relationship to curriculum, in which teachers are called upon to be receptive, that a non-violent element to the teaching-learning relationship may be allowed to enter.

Klein's (1992) case study, 'The importance of symbol-formation in the development of the ego', outlines what this failure looks like and the impact it has on the ego-development of a 4-year-old autistic boy, Dick. Klein has much to teach her readers about her role as a pedagogue, insofar as it is her function as a psychoanalyst to help the child make meaning and symbolize his world. At the same time, Klein also offers her audience a window through which to see how this 'brutal' process is also inflected with an 
openness and receptivity to the vicissitudes of Dick's vulnerabilities. As well, the case study highlights the work in which Klein and Dick are engaged when the demand for 'learning to become' is front and centre. The study also gives educators cause for concern, for in asking students to alter themselves, do teachers replay the students' earlier struggles with egoformation outlined by Klein?

\section{Learning from Klein and Dick}

Klein's case study is a foray into how the subject learns to become an ego. The journey she embarks on is quite compelling, for Klein depicts not only the difficulties, trials and anxieties that face Dick, but reveals something of her own role in inducing these difficulties and her attempts at allaying them. For these reasons, looking in detail at Dick's ego-development may help educators understand some of the structures that emerge within the educational setting itself. Klein notes three movements in becoming an ego: initial non-responsiveness; induced anxiety; and, finally, the turn to symbolization in order to tolerate this anxiety.

Klein (1992) describes Dick as a 4-year-old boy who functions, in terms of vocabulary and emotional relations to his surroundings, at the level of a 15-month-old child. He fails to communicate any feeling, and is now thought to have been an autistic child at the time of his analysis. Klein offers an account of how the ego comes into being for Dick through his ability to form symbols and make meaning. During his first session with Klein, Dick refrains from all outward emotional activity, be it hiding, shying away, crying, or playing. He runs around Klein as 'if I were a piece of furniture' (p. 222). Klein concludes her initial portrait of Dick with the claim that 'Dick's behaviour had no meaning or purpose, nor was any affect or anxiety associated with it .... [His] ego had ceased to develop phantasylife and to establish a relation with reality' (pp. 222, 224). She regards him as being absolutely incapable of aggression, and he refuses to chew up his own food, seemingly unwilling to even allow this little aggression into his life. Although she continually reminds the reader throughout the narrative that the child was affectless and disinterested, she, nevertheless, also notes his interest 'in trains and stations and also in door-handles, doors and the opening and shutting of them' (p. 224) - a point to which I shall return below.

Because of Dick's incapacity to symbolize his fantasies through play, Klein (1992) notes that she has to shift her technique. ${ }^{9}$ Instead of focusing on what the child acts out through his play, Klein must find a means of provoking play and, thus, symbolization and fantasy. 'His lack of interest in his environment ... [was] only the effect of his lack of a symbolic relation to things. The analysis, then, had to begin with this, the fundamental obstacle to establishing contact with him' (p. 225). Her analysis becomes focused on disrupting Dick's enclosed sense of self, and she begins a strategy that, to put it in Levinasian terms, brings him more than his 'I' can contain, or, as Klein would put it, induces anxiety. This marks the second phase of Dick's 
learning to become. The demand is the familiar pedagogical one, tinged with coercion: to provoke the child into making meaning.

Klein (1992) takes the rather brazen step of placing two trains on a table before Dick, stating that the big train is 'Daddy train', the little one 'Dick train'. This move acts as more than a provocation, appearing invasive and coercive, perhaps even 'brutal', as Lacan (1991a: 68) would suggest. To quote from Klein: 'Thereupon he picked up the train I called "Dick" and made it roll to the window and said "station". I explained: "The station is mummy; Dick is going into mummy"” (p. 225).

Dick then runs into the dark hallway between the entryway doors of the room, and says the word 'dark'. After repeating this several times, Klein reports:

I explained to him: 'It is dark inside mummy. Dick is inside dark mummy'. Meantime he picked up the train again, but soon ran back into the space between the doors. While I was saying he was going into dark mummy, he said twice in a questioning way: 'Nurse?' I answered: 'Nurse is soon coming', and this he repeated and used the words later quite correctly, retaining them in his mind (p. 225).

However, it is in the third analytic visit where Dick begins to make a sustained symbolic relation, marking the third phase in 'learning to become'. Instead of running between the doors after picking up the train, Dick hides behind a piece of furniture and becomes seized with anxiety. It is at this point that Dick, for the first time, calls out for Klein to come to him.

This is the turning-point in the analysis, the moment when Dick begins to formulate a relation to the outside world, occasioned, according to Klein, by his intense anxiety. This then leads Dick to an increased vocabulary and heightened sense of emotional investment in Klein and his nurse. Indeed, Dick begins to play, begins the work of symbolization. The work of making meaning through play is a strategy that allows Dick to tolerate his anxiety. The ego-work that Dick is engaged in brings with it the pain of having to accept difference, to receive what Klein has to offer him, which is always already outside himself. As Levinas might say, Klein has ruptured Dick's own containment, pierced his own self-identity. Now, in a face-to-face relation with difference, Dick struggles to overcome (what Klein would call a 'working over') the profound vulnerability aroused by his anxious state.

The analysis continues and Dick begins to act out his fantasies with regard to his parents. As Jacobus (1995: 132) notes in her close reading of the case study, at each turn, Klein, with 'characteristic literalness', gives him 'signs in exchange for toys'. Klein (1992) re-tells Dick what he is doing, interpreting his play as he performs it, rather than waiting for patterns of repetition to emerge in the play itself. This is how she describes the modification of her technique:

In general, I do not interpret the material until it has found expression in various representations. In this case, however, where the capacity to represent it was almost entirely lacking, I found myself obliged to make my interpretations on the basis of my general knowledge .... I succeeded in activating anxiety and other affects. The representations then became fuller 
and I soon acquired a more solid foundation for the analysis, and so was able gradually to pass over to the technique that I generally employ in analysing little children (pp. 228-229).

Her technique centres on giving to Dick words that activate anxiety and affect. Klein believes that it is only through such crises that Dick can begin the process of becoming. But, she also gives him something more. She introduces him to significations that come from the Other, and, therefore, places him in a potential social relation, an ethical relation. Dick, through his receiving 'beyond the capacity of the I', beyond what he is at present, begins to make a relation with his own unconscious desires and conflicts, at the same time as he makes a relation to the otherness that is Klein.

This is crucial. For, not only does Dick establish a relation to the outside world via a relation to the Other that is Klein, he must also establish a relation to the otherness of the unconscious. What Klein demonstrates here is that the latter relation cannot take place prior to the former. It is through the Other that is Klein, through the social relation, that Dick's own relationship with himself is provoked. This suggests to me that it is not only Klein's words that are important, but the very presence of two beings which conditions Dick's receptivity of words.

But, what does this suggest about Klein's role as a pedagogue? What can educators learn from her? One can certainly see the 'brutality' of her invasive strategy. At least in her recounting of the analysis, Dick is continually pushed toward making a relationship to the words she offers, anxieties are incited, and she fosters sublimation through her abnormally persistent interpretations of his fantasies. These are the key ingredients in Dick's developing symbolic relationships to his surroundings. 'Learning to become' is indeed presented as a violent process, where Dick not only struggles to enter into a social relation with the Other, but does so with profound affective difficulties, evident in his calling out to Klein in utter despair. But, even in this case, in which the violence of pedagogy, of 'learning to become', is so transparent, there is, nonetheless, evident a mode of interaction that swims against the current of Klein's seeming invasiveness, and it concerns Dick's initial interest in trains, doors, and handles.

There is no question that Klein brings Dick more than he contains, that she 'teaches' him; she infuses the trains and doors with a signification truly 'outside' what Dick is capable of articulating on his own. As Jacobus (1995: 137) observes:

This all-too-literal naming is the glue that makes language 'stick' to the trains, door handles, and 'dark' of little Dick's imaginary. Klein's words 'graft' the Oedipus complex onto little Dick's arrested symbol-making capacity.

However, the 'grafting' only takes root because it already builds on a nascent interest. Dick has some-albeit tentative-capacity to begin the work of semiosis through his interest in trains, doors and handles in the first place. What is of note to education is that, in some measure, Klein has been receptive to this interest and uses it in order to create a logic or structure for Dick's fantasies to take hold. Moreover, she alters her own 
technique, her own mode of symbolization in order to do so. She gives Dick a social relation with a difference, a signifying structure, to which he attaches his fantasy life and works through his anxiety.

In some ways, Klein is receptive to the otherness Dick returns to her. ${ }^{10}$ She is open to working with the defences Dick presents, and, although some people might say she errs on the side of giving Dick too much to handle (pun intended), of creating excessive anxiety, what Klein is also able to recognize is that it is Dick who has made meaning with the tools and structures she has offered him. It is in Dick's failures to become, his hesitations, anxieties, indifferences and non sequiturs in which Klein's openness reveals itself. As a psychoanalyst, she knows that Dick must learn to tolerate his own anxiety through symbolic attachments, but also knows that she has a role to play in bringing him more than he can contain and, perhaps, more than he can bear to know. Hers is not a maieutic method, where she is but eliciting that which Dick already knows, but a pedagogy of provocation and disruption that responds to the specificity of Dick's interests and needs. She listens for possibilities of slippage in meaning, in the breakdown of communication, in the glances he gives her, in the associations of word and action made through play, and returns them to Dick, returns them through the discourse of the Other. I want to return to a claim made earlier, that it is not the words themselves that provoke Dick's anxiety and subsequent symbol-formation, but the fact that they come via the Other, via the presence that is Klein. To recall Levinas (1969): 'The face speaks. The manifestation of the face is already discourse' (p. 66); and 'Discourse is ... the experience of something absolutely foreign ... a traumatism of astonishment ... . This absolutely foreign alone can instruct us' (p. 73). It is just such a traumatism that Dick received, and one which, in my view, all students may at times receive from their teachers.

Klein's case study suggests to me that teachers, in trying to encourage students to engage in meaning-making activity, take a number of risks, the incitement of anxiety being a major one. What she helps educators to understand, in my view, is the delicacy of engaging students in their interests, in offering them interpretations or theories of their experiences, in providing for them a structure through which they might think themselves in relation to the world. Even when teachers do offer interpretations and structures through texts, films and the like, even when teachers refrain from offering personal beliefs, curriculum, none the less, largely comes via the Other that is the teacher; it comes from that which is foreign, risking, to echo Levinas words once again, a 'traumatism of astonishment'. This traumatism is not just about being 'bowled over' or being in awe of something, but about being traumatized, about risking the security of one's self-identity, about facing the possibility of becoming altered. It is precisely within this context of risk that the delicate nature of teaching arises. But, what might attending to the delicacy involved in teaching look like?

Klein, one could argue, employed anything but a delicate touchinstead, forcing upon Dick her own prescriptive interpretations in order to provide a structure for meaning to take hold. Yet, as I have suggested, her interaction with Dick is not reducible to the words she says to him; she 
is also open, and, therefore, subject to Dick's unique responses of fear and anxiety. She goes to him when he calls; she plays with him when he enters the analytic session; she responds to the looks he gives her; she talks to him when he is at play and, at times, cuddles him when he is overwrought. What teachers might learn from Klein, and psychoanalysis more generally, is not a 'laundry list' of behaviours that replicate Klein's actions, but a concern to be attentive to the range of possible responses students generate out of their own positions of vulnerability and to be sensitive to the profound singularity of the situation at hand. The quality of one's response to another's particular vulnerable condition is central and not merely incidental to learning; this is particularly the case when teachers, as the ones who 'bring more than I contain', are implicated in this very vulnerability in the first place. Understanding teaching as a delicate engagement means that the emphasis is not on specific strategies or behaviours for 'optimal' interaction (this would be not unlike an applied ethics with a set of rules to determine behaviour), but an attentiveness to the exposure and riskiness students face in their everyday experiences of learning (more akin to an implied ethics where the nature of interaction is found within the pedagogical realm itself). Such an understanding means, on the one hand, accepting the fragility of students' identities as they seek to develop meaning for themselves with oft-times heightened emotional intensity (e.g. the beginning teacher who is genuinely fearful of the students she is about to teach; the young child who anxiously awaits the teacher's approval for getting the right mathematics answer; the graduate student who falls thoroughly in love with an idea). On the other hand, such an understanding also requires acknowledging that one's teaching, as a relation to otherness, is precisely what provokes (but does not determine) such fragility and intensity to begin with. The delicacy of teaching, then, with its emphasis on responding to the unique Other, is at once a curricular and ethical matter.

\section{Curriculum and ethical possibilities}

Where does this leave educators in contemplating the possibility for ethics in education? Where might this lead in terms of thinking about the nature and place of curriculum?

I have explored what an 'implied ethics' might mean for educationthat is, looking to the particularities of the pedagogical encounter, the relationships between teachers and students, between Klein and Dick, to see what might be learned from them regarding the ethical significance of education. Even within a pedagogy structured by a demand for 'learning to become', a learning that, often under the rubric of 'socialization', is not so innocent or painless as educators would perhaps like to believe, there is, nonetheless, a place for ethicality. There are two pedagogical contingencies that lend ethical significance to an implied ethics for education.

First, there is the uncertainty of the pedagogical encounter itself, where the meanings students create for themselves cannot be foreseen, where 'learning to become' is not a seamless project of success. As Klein's case study demonstrated, it was in the miscues, associations and interests found 
in Dick's play, and in his failures to become an ego, that compelled her attention and responsiveness, that led to a change in technique. This attentiveness to unforeseeable detail and meaning also holds for the educational realm. It is from an 'initial position of uncertainty', as Stone (1995: 184) suggests, that 'openness, humility and trust' become possible. As teachers and students, we tentatively come together in anticipation of an encounter of which we cannot predict the outcome; the exchanged looks, the tones of voice, the artifacts of curriculum, the passion of opinion, the indifference to a question, the time and space to be negotiated, the desire for love and recognition, all of this and more comprise the tiny, yet colossal, details that shape and shake the ground upon which educational edifices are built. Such uncertainty in our interactions carries serious ethical weight, for, if such uncertainty is inevitable, then the quality of response to the Other is rooted in shifting social relations rather than in solely abstract adherence to ethical rules or principles. Moreover, in terms of an implied ethics, such uncertainty compels educators to develop thoughtful approaches to the Other, rather than carry out a set of pre-determined behaviours that tell teachers 'this is what you should do'. Although some guidelines are unavoidable (and legally necessary), mere rules alone do not assure ethical, non-violent interactions.

A second contingent feature of implied ethics is the relation the Self has to the Other, which signals the importance of sociality and ethicality to education and also highlights that it is through this sociality that a different relationship with one's self may be established. Words, information and teaching are not disembodied within the pedagogical encounter, but are made available through the Other and, as such, the encounter speaks to the necessarily social aspect of teaching and learning. As I have suggested, it is the potentiality of this relationship to do violence that makes it susceptible to ethicality right from the start. Moreover, as Dick's analysis revealed, the kind of provocation and disruption to self-identity that the Other brings to the I sets the conditions, in the form of anxiety or traumatism, for profound alteration of the ego; anxiety itself becomes an otherness to which the subject has to make a relationship. As a way of thinking about ethics through education, the Self-Other relationship is crucial for understanding how profoundly teachers can be implicated in the lives of their studentsoften unwittingly, of course-and enables teachers to reflect on how their everyday responses are always already ethically laden.

What I have been outlining here carries with it a tacit critique of the Socratic model for education, whereby learning is rendered through a process of dialogue and questioning. This midwife model is often a cornerstone both for progressive and critical approaches to education: the teacher is merely there to guide students to discover knowledge for themselves. This appears to be a model of limited pedagogical intervention, beginning from students' own interests and building from there. But, what is omitted from this account of midwifery or facilitation is how the questions always come via the Other, via an Other that is not reducible to the Self. The epistemological emphasis on self-knowledge blankets over the dialogical relation as a social and ethical relation between two non-synchronous subjects. Dialogical exchange is not seen to be about 
confronting otherness, but about eliciting the implicit knowledge the student already has. Learning, thus, neither dislocates nor interrupts, it merely gives definition to what is already there. One does not learn, therefore, from teaching, from a relation to otherness-as Socrates himself remarks to Meno, 'there is no teaching, but only recollection' (Plato 1937: 82a, 361).

Instead, what I am suggesting here is that learning is accompanied by a receptivity to the Other, by a receptivity to the difference returned to the learner through the practice of teaching. As Felman's (1997: 28) commentary on Lacan indicates, 'Coming from the Other, knowledge is, by definition, that which comes as a surprise'. In this way, learning occasions states of affect that are disturbing and, perhaps, painful, making teachers and students incredibly vulnerable to one another. Being open or receptive to the Other suggests a mode of relationality that may be very difficult to sustain. My own position, however, is that responsiveness to the Other can counter the harm wrought by pedagogy's own demands for alteration. Perhaps receptivity and total non-violence is not humanly or psychologically always possible-after all, teachers have defences too-but if educators are going to live well in the uncertainty of their classrooms and interact in less harmful ways that respect the otherness of the Other, then are they not compelled by virtue of their roles as teachers who do 'bring more than I contain', who do provoke and disrupt the security of students' selves, to be responsible-to be responsive? As stated above, such receptivity does not only concern the Other, but affects one's relationship to one's self. In this regard, part of the ethical relation involves an openness to considering one's own anxieties and defences and how they appear in the Self-Other relation.

At the risk of losing sight of the place of curriculum in pedagogical encounters, what is recentred in this discussion is the place of teaching and its ethical significance. Indeed, I have implied that it is important to think curriculum through teaching, just as I have been thinking ethics through education. Curriculum in this view is neither just a cultural or political instrument divorced from the concrete practices of teaching, nor a solipsistic rendering of personal or autobiographical knowledge. Instead, curriculum passes through the very sociality of Self and Other, replete with uncertainties and diverse contexts. Moreover, it is precisely because it passes through this social relation that curriculum can become a tool for the most oppressive ends, to which any colonial education will attest. It is not only the 'content' of curriculum that matters, but the articulatory practices through which difference is symbolized (Todd 1997). From the perspective of the learner, curriculum comes via the Other that is the teacher in the form of new ideas, concepts and texts; yet the meaning he or she makes out of such material can never be secured beforehand. As a feature of such SelfOther interaction, curriculum lends substance to the process of 'learning to become': it is the symbolic raw material that students use, discard or rewrite in making meaning for themselves. Curriculum is, thus, fundamental to the symbolic elaboration necessary to ego-formation.

In thinking curriculum through teaching, curriculum also participates in the pedagogical contingencies for ethicality already outlined: in both the uncertainty of meaning and the Self-Other relation. With regard to the 
latter, curriculum cannot appear as a mirror in which students simply see themselves reflected. This would, in effect, serve to erase otherness, each self looking only for its own reflection, reading texts and listening to people to see how they are 'just like me'. On the surface, this view of curriculum I am elaborating seems to fly in the face of calls for a more inclusive curriculum, where education is premised on just such a capacity to see the commonalities between people, or when under- and mis-represented groups seek to include curricular materials that more adequately reflect their reality and with which they can identify. However, I maintain that even in the face of such necessities in combatting social inequities, one needs to be vigilant about what such curricular moves may be assuming. For instance, mirroring responses may in fact collapse difference within and between communities. It is not that identifications are not necessary or of no value to questions of community-building and for disrupting systems of discrimination, but with regard to education, they alone cannot provide the conditions for ethicality, for a non-violent relationship to the Other where the otherness of the Other is left intact and unharmed. Instead, seeing curriculum as part of a much broader practice of social (and ethical) interaction suggests that focusing on more inclusive representation for the purposes of identification is not sufficient-and not only because such meaning-making may go off in unpredictable directions. The implication here is that curriculum needs to be more thoroughly considered as part of the quality of human response between teachers and students, as part of the delicacy of engaging students, rather than as a fixed set of representations.

In terms of the pedagogical contingency of uncertainty, curriculum is itself unstable, for it continually exceeds the bounds of its 'content' in terms of textbooks, films or literature. Instead, understood as partaking in a subject's idiosyncratic capacity to symbolize, in a subject's unconscious proclivity to make meaning, curriculum can include a wide range of objects, thoughts, expressions, and affects. As Phillips (1998: 412) suggests:

From a psychoanalytic point of view, I have my conscious preoccupations and ambitions, and these make me more or less educable. But, I also have my unconscious desire and affinities-tropisms and drifts of attention-that can be quite at odds with my conscious ideals. I may go to a lecture on psychology and be fascinated; but I may dream that night about the earrings of the woman sitting next to me; which, if I were to associate to this detail in the dream might, like Proust's legendary madeleine, open up vistas of previously unacknowledged personal history.

On another level, curriculum comes from outside the subject, but not necessarily via the Other that is the teacher; rather it also comes via the otherness of the Self, the unconscious. The play of uncertainty does not merely lie within the teacher-student relation, but within a different kind of relationship to the unconscious, as the preceding discussion on Klein and Dick has revealed. What is significant for curriculum here is how it at once participates in ego-formation as well as in the subject's creative capacity for unconscious representation. Thus, curriculum gives form and substance to the delicate relations that mark the process of 'learning to become'. 
When one reflects upon the conditions of violence and non-violence present in the pedagogical encounter, the question of what constitutes the possibilities of response may seem easy to ask, but far more difficult to answer. Unfortunately, the trauma of wetting oneself in front of the class, or of witnessing such an event, is neither extraordinary nor rare. Yet, it does seem to call out for a responsiveness that is at minimum both sensitive and mindful of otherness. In exploring here some of the assumptions guiding teaching practices and in asking educators to consider the uncertainty of meaning and the vulnerabilities often displayed in the classroom, I am well aware that teachers and learners are already stretched to capacity in the hectic day-to-dayness of what it means to teach and to learn. However, if teaching is not going to abandon the ethical significance of its role in 'bringing more than I contain', perhaps the work of an implied ethics resides in teachers being able to live both within and beyond their means, both within and beyond their capacity, simultaneously.

\section{Acknowledgements}

I acknowledge the thoughtful comments made by Roger Simon, Deborah Britzman, Alice Pitt, Carol Schick and Stan Nemiroff on earlier versions of this paper. Paula Pastor-Schonberger kindly granted me permission to include an extract from her essay and inspired me to reflect on the demands of education in my own writing and teaching.

\section{Notes}

1. For the remainder of the paper, I use the term 'learning to become'. Although this is not a phrase Castoriadis uses himself, in my use of it I am indebted to his broad understanding both of pedagogy and of the ego as a social-historical institution.

2. Castoriadis (1991: 149) writes, 'The minimal requirement for this process to unfold is that the institution provide the psyche with meaning ....

3. For a discussion on how education historically has performed coercively, see Block (1995). Leavitt and Power (1997) offer a Foucaultian discussion of how children's bodies are disciplined in daycare settings. Both of these articles illustrate, in different ways, the type of violence I am associating with 'learning to become'. Although the scope of this paper does not permit a full discussion of violence, it is important to signal that this is neither a metaphorical usage of the term, nor one designed to erase the differences between specific acts of violence (e.g. neglect, humiliation, fear, abuse, torture). My emphasis here is on the external force or strength that has the power to subject, that compels people to learn and become. In this sense, education by its very socializing function and by its mission to change how people think and relate to the world, enacts a violence that is necessary to the formation of the subject (this is what is meant by 'formation'). In both the metaphysical formulations of Derrida and Levinas, on the one hand, and the psychical formulations of psychoanalysis on the other, violence is a necessary condition of subjectivity. The question is not so much whether education wounds or not through its impulse to socialize, but whether it wounds excessively and how we as teachers might open ourselves to non-violent possibilities in our pedagogical encounters.

4. Klein believes, following Ferenczi (e.g. 1952), that identification is a precursor to symbolism (echoed and developed further in Lacan's (1991b) understanding of the imaginary and the symbolic). As will be evident below, however, Klein deviates slightly 
from this view in her emphasis on the primary role anxiety plays in both identification and symbolization. It is this emphasis that makes her work, in my view, central for working through the anxieties attached to learning.

5. Cornell (1992: 62) offers a useful definition of the non-violent nature of the ethical relation: 'Again by the ethical relation I mean to indicate the aspiration to a non-violent relationship to the Other, and to otherness more generally, that assumes responsibility to guard the Other against the appropriation that would deny her difference and singularity'.

6. Levinas is proposing something quite different from Buber's conception of the I-Thou which is based on a symmetrical and shared subjectivity. Similarly, current conceptions of the ethic of care in education focus on the resemblance and reciprocity between ethical subjects, despite the fact that each subject may have a different role to play in the ethical relationship. This is clearly contrary to the emphasis Levinas places on the radical alterity of the other person whereby responsibility for the Other is nonreciprocal and does not anticipate any form of mutual interaction.

7. I am following Levinas' usage of ' $I$ ' and 'ego' to refer to the structure of being that signifies the totality of the self over time. While in psychoanalytic theory, particularly that influenced by Lacanianism, the $I$ is a fundamentally different structure than the ego, there is at times some slippage between the I and ego in Levinas' work.

8. Interestingly, however, Socrates' teaching, particularly that displayed in the Meno, can be read against his own declarations. In his encounter with the slave boy, it is clear that because of Socrates' skills as a wordsmith he is able not only to condition the responses offered by the boy, but also necessarily participates in an exchange that is already premised on gaping differences and radical otherness between the two people involved.

9. This shift in technique really becomes a redefinition of technique that seeps into all of Klein's clinical work after this time.

10. In Grosskurth's (1986) biography of Klein, she mentions how as an adult 'Dick' recalls Klein's affection to him in times of need. Klein, however, continued in her theoretical writing to deem such displays of affection as improper.

\section{References}

Bauman, Z. (1993) Postmodern Ethics (Oxford: Blackwell).

BLOCK, A. (1995) 'It's alright, Ma (I'm only bleeding)': education as the practice of social violence against the child. Taboo: Fournal of Culture and Education, 1 (1), 123-142.

Britzman, D. P. (1998) Lost Subjects, Contested Objects: Toward a Psychoanalytic Inquiry of Learning (Albany, NY: SUNY Press).

Castoriadis, C. (1987 [1968]) The Imaginary Institution of Society, trans. K. Blamey (Cambridge: Polity Press).

Castoriadis, C. (1991) Power, politics, autonomy. In C. Castoriadis (ed.), Philosophy, Politics, Autonomy: Essays in Political Philosophy, trans. D. A. Curtis (Oxford: Oxford University Press), 143-174.

Castoriadis, C. (1997 [1990]) Psychoanalysis and politics. In C. Castoriadis (ed.), World in Fragments: Writings on Politics, Society, Psychoanalysis, and the Imagination, trans. D. A. Curtis (Stanford, CA: Stanford University Press), 125-136.

Cornell, D. (1992) The Philosophy of the Limit (New York: Routledge).

Derrida, J. (1978) Violence and metaphysics: an essay on the thought of Emmanuel Levinas. In J. Derrida (ed.), Writing and Difference, trans. A. Bass (Chicago: University of Chicago Press), 79-153.

Dewey, J. (1969 [1938]) Experience and Education (New York: Collier).

Felman, S. (1997) Psychoanalysis and education: teaching terminable and interminable. In S. Todd (ed.), Learning Desire: Perspectives on Pedagogy, Culture, and the Unsaid (New York: Routledge), 17-43.

Ferenczi, S. (1952 [1912]) Symbolism. In S. Ferenczi (ed.), First Contributions to PsychoAnalysis, trans. E. Jones (London: Hogarth Press), 253-281.

Grosskurth, P. (1986) Melanie Klein: Her World and Her Work (Cambridge, MA: Harvard University Press). 
Jacoвus, M. (1995) First Things: The Maternal Imaginary in Literature, Art, and Psychoanalysis (New York: Routledge).

Klein, M. (1992 [1930]) The importance of symbol-formation in the development of the ego. In M. Klein (ed.), Love, Guilt and Reparation and Other Works 1921-1945. The Writings of Melanie Klein, Vol. 1 (London: Karnac Books), 219-235.

Lacan, J. (1991a) The Seminar of Jacques Lacan: Book I: Freud's Papers on Technique, 1953-1954, ed. J.-A. Miller, trans. J. Forrester (New York: Norton).

Lacan, J. (1991b) The Seminar of Facques Lacan: Book II: The Ego in Freud's Theory and in the Technique of Psychoanalysis, 1954-1955, ed. J.-A. Miller, trans S. Tomaselli and J. Forrester (New York: Norton).

LeavitT, R. L. and Power, M. B. (1997) Civilizing bodies: children in day care. In J. L. Tobin (ed.), Making a Place for Pleasure in Early Childhood Education (New Haven, CT: Yale University Press), 39-75.

Levinas, E. (1969 [1961]) Totality and Infinity: An Essay on Exteriority, trans. A. Lingis (Pittsburgh, PA: Duquesne University Press).

Levinas, E. (1985 [1982]) Ethics and Infinity, trans. R. A. Cohen (Pittsburgh, PA: Duquesne University Press).

Levinas, E. (1987 [1979]) Time and the Other and Additional Essays, trans. R. A. Cohen (Pittsburgh, PA: Duquesne University Press).

Phillips, A. (1998) Learning from Freud. In A. O. Rorty (ed.), Philosophers on Education: New Historical Perspectives (New York: Routledge), 411-417.

Plato (1937) Meno. In The Dialogues of Plato, Vol. 1, trans. B. Jowett (New York: Random House), 349-382.

Simon, R. I. (1992) Teaching Against the Grain: Texts for a Pedagogy of Possibility (Toronto: OISE Press).

Stone, L. (1995) Narrative in philosophy of education: a feminist tale of 'uncertain' knowledge. In W. Kohli (ed.), Critical Conversations in Philosophy of Education (New York: Routledge), 173-189.

TodD, S. (1997) Looking at pedagogy in 3-D: rethinking difference, disparity and desire. In S. Todd (ed.), Learning Desire: Perspectives on Pedagogy, Culture and the Unsaid (New York: Routledge), 237-260.

Wien, C. A. and Dudley-Marling, C. (1998) Limited vision: the Ontario curriculum and outcomes-based learning. Canadian Fournal of Education, 23 (4), 405-420. 